Article

\title{
Bit- and Power-Loading-A Comparative Study on Maximizing the Capacity of RSOA Based Colorless DMT Transmitters
}

\author{
Simon Arega Gebrewold ${ }^{1,2, *}$, Romain Bonjour ${ }^{1}$, Romain Brenot ${ }^{3}$, David Hillerkuss ${ }^{1,4}$ \\ and Juerg Leuthold ${ }^{1}$ \\ 1 Institute of Electromagnetic Fields (IEF), ETH Zurich, 8092 Zurich, Switzerland; rbonjour@ethz.ch (R.B.); \\ david.hillerkuss@huawei.com (D.H.); Juergleuthold@ethz.ch (J.L.) \\ 2 Now with RANOVUS GmbH, Nordostpark 07, 90411 Nuremberg, Germany \\ 3 Thales Research and Technology and CEA Leti, Route de Nozay, a Joint Lab of Alcatel-Lucent Bell Labs France, \\ III-V Lab, 91460 Marcoussis, France; romain.brenot@3-5lab.fr \\ 4 Now with Huawei Technologies Duesseldorf GmbH, Optical \& Quantum Laboratory, Riesstrasse 25-C3, \\ 80992 Munich, Germany \\ * Correspondence: simon@ranovus.com; Tel.: +49-176-9093-9230
}

Received: 6 August 2017; Accepted: 4 September 2017; Published: 27 September 2017

\begin{abstract}
We present a comparative study of the capacity increase brought by bit- and power-loading discrete multi-tone (DMT) modulation for low-cost colorless transmitters. Three interesting reflective semiconductor optical amplifier (RSOA) based colorless transmitter configurations are compared: First, an amplified spontaneous emission (ASE) spectrum-sliced source; second, a self-seeded RSOA fiber cavity laser (FCL) and third, an externally seeded RSOA. With bit- and power-loaded DMT, we report record high line rates of $6.25,20.1$ and $30.7 \mathrm{Gbit} / \mathrm{s}$ and line rates of 4.17, 10.1 and $24.5 \mathrm{Gbit} / \mathrm{s}$ in a back-to-back and in a $25 \mathrm{~km}$ nonzero dispersion shifted fiber (NZDSF) transmission experiments for the three transmitter configurations, respectively. In all the experiments, BER (bit error ratios) below an FEC (forward error correction) limit of $7.5 \times 10^{-3}$ were achieved.
\end{abstract}

Keywords: bit- and power-loading; colorless transmitter; discrete multi-tone (DMT); reflective semiconductor optical amplifier (RSOA); WDM-PON

\section{Introduction}

Maximizing the bit-rate of colorless, inexpensive and "poorly" performing transmitters has become a research topic on its own. This is of particular importance in wavelength division multiplexed (WDM) passive optical networks (PONs) that are considered a possible solution to cope with the capacity surge in access networks [1,2].

WDM-PONs are being considered for applications requiring bidirectional high capacity and secure links. WDM-PONs are therefore ideal solutions to serve fiber to the home and building (FTTH/B) users with high capacity demands and also ideal to cover the needs of mobile fronthaul (fiber to the antenna, FTTA) [3,4]. The latter is characterized by small cell sizes with dense base stations. If WDM-PON are to be mass deployed, large quantity of wavelength specific optical network units (ONUs) would be required, which highly complicates the inventory. Thus, the challenge is to develop ONU transmitters that allow the installation of identical devices across all subscribers. The solution are colorless transmitters that operate across a broad wavelength range, while their specific operation wavelength is controlled by an external factor [5-8]. Installing identical colorless transmitters across all ONUs consequently, reduces the number of specialized components-thus simplifying the inventory. In addition, relatively low-quality mass producible colorless sources will make WDM-PON more economical. 
For low-cost colorless transmitters, the specific operating wavelength can be controlled by two main methods. A filter at a remote location can automatically choose the transmission wavelength of an ONU $[9,10]$. Alternatively, colorless operation can also be implemented by using an external seed laser placed at the central office (CO) to determine the upstream wavelength [11-16].

One promising colorless source is based on reflective semiconductor optical amplifiers (RSOAs). RSOAs are ideal sources as they offer a broad optical bandwidth at a low cost. There are three main architectures to integrate RSOAs in a WDM-PON as upstream (US) transmitters at the ONU. A theoretical and experimental comparison of the three architectures has been presented in [17].

- The simplest and most economical scheme is using RSOAs as amplified spontaneous emitters (ASE) source in a spectrum-sliced scheme, as shown in Figure 1a. The US signal is directly modulated onto the ASE of the RSOA. At the remote node (RN), a WDM filter slices the modulated ASE, passing only the assigned sub bands from each ONU to the central office $(\mathrm{CO})[18,19]$. The scheme is low-cost and simple, but so far only bit rates below $1 \mathrm{Gbit} / \mathrm{s}$ have been achieved for each wavelength, with this scheme. The limitations of this scheme are high filtering losses and susceptibility to chromatic dispersion due to a broad optical spectrum.

- Another cost-efficient source-however with improved performance-is the self-seeded RSOA fiber cavity laser (RSOA-FCLs) as suggested in $[20,21]$ and depicted in Figure $1 \mathrm{~b}$. In this case, a mirror is placed at the RN behind the WDM filter. This establishes a feedback mechanism to the RSOA to form a Fabry-Perot laser resonator. The operating wavelength of each ONU's RSOA-FCL is determined by the WDM filter port it is connected to. This passive assignment of the emission wavelength simplifies the wavelength control. Thus far, RSOA-FCL have shown to transmit up to $10 \mathrm{Gbit} / \mathrm{s}[22,23]$.

- The highest performance-however, a relatively expensive scheme-is the externally seeded RSOA, shown in Figure 1c. Here, a bank of lasers, one for each ONU, is installed at the CO. The WDM filter at the RN redistributes the individual cw (continuous wave) laser lines to each ONU. At the ONUs the RSOAs amplify the seeding light and encode the US signal. Externally seeded RSOAs have already shown transmission beyond $20 \mathrm{Gbit} / \mathrm{s}$ with pulse amplitude modulation (PAM) [24] and more than 25 Gbit/s using discrete multi-tone (DMT) [14,25]. However, in both cases, controlled offset filtering by a WDM filter or an additional delay line interferometer was required, which makes the system sensitive to any wavelength drift. In addition, the extra lasers at the $\mathrm{CO}$ increases cost and energy consumption.

In these three schemes, the modulation bandwidth limitation of RSOAs is a challenge that has to be addressed to fulfill the high data rate requirements of WDM-PONs. There have been different approaches to alleviate this issue. One solution is to improve the speed of the RSOAs by optimizing the physical design of the device [26]. Initial implementations of RSOA, mainly in the externally seeded scheme, employed non-return-to-zero (NRZ) amplitude-shift keying (ASK) modulation with either electronic $[27,28]$ or optical signal processing $[28,29]$ or a combination of electronic and photonic signal processing [30] to demonstrate $10 \mathrm{Gbit} / \mathrm{s}$. Return-to-zero (RZ) and NRZ are compared in [31]. Advanced modulation formats have also been demonstrated for higher spectral efficiency with electronic and optical equalization in [12]. Polar RZ PAM4 with delay interferometer optical signal processing has achieved $20 \mathrm{Gbit} / \mathrm{s}$ [32]. Recently, multicarrier schemes such as adaptive orthogonal frequency division multiplexing (Adaptive-OFDM) [33] have been implemented for improved performance of the externally seeded scheme. Adaptive OFDM [25] and bit- and power-loaded DMT [14], both with optical equalization have already demonstrated beyond $25 \mathrm{Gbit} / \mathrm{s}$ transmission. 
(a) ASE Spectrum-Sliced WDM-PON

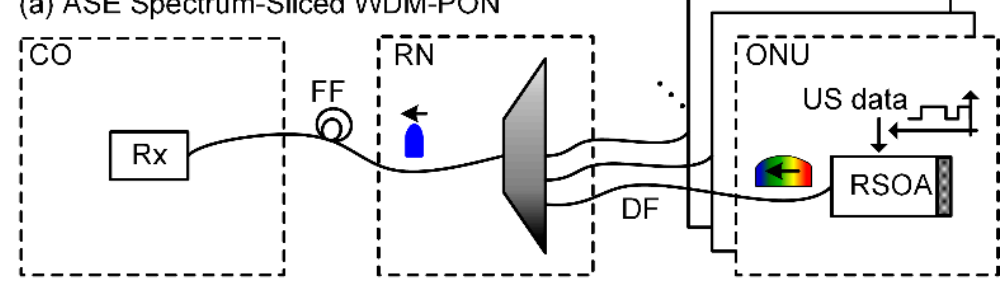

(b) Self-Seeded RSOA-FCL WDM-PON

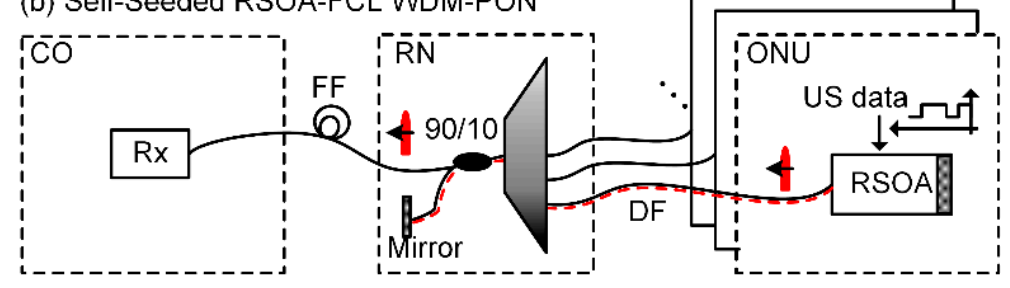

(c) Externally Seeded RSOA WDM-PON

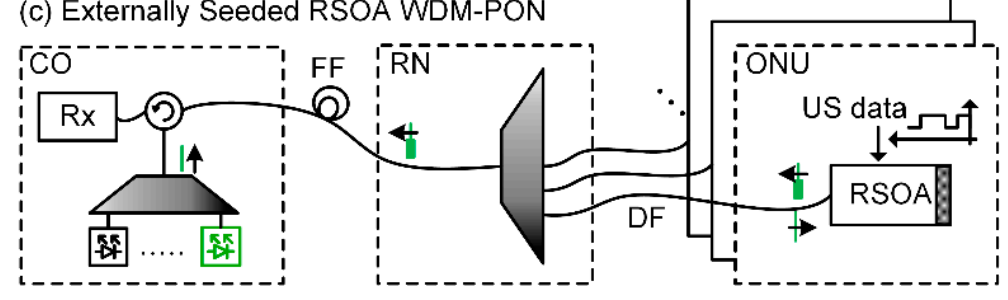

Figure 1. Wavelength division multiplexed passive optical network (WDM-PON) topologies with reflective semiconductor optical amplifier (RSOA) based colorless upstream (US) transmitters: (a) Amplified spontaneous emitter (ASE) spectrum-sliced transmitter: the US signal is directly modulated on to the ASE of the RSOA. The WDM filter at the remote node (RN) passes only the assigned sub band from each RSOA at the optical network units (ONUs); (b) Self-seeded RSOA-FCL (fiber cavity laser): a Fabry-Perot cavity indicated by the red dashed lines is formed between the RSOA and a mirror at the RN. The cavity is embedded in the distribution fiber (DF) of the PON; (c) Externally seeded RSOA: a laser at the central office (CO) seeds the RSOA at the ONU. The RSOA encodes the US signal onto the seed laser line. In all case, the ONUs are connected by the DF to the RN. The RN consists of the WDM filter and it is connected to the CO through the feeder fiber (FF).

In general, DMT has been used to maximize capacities of bandwidth limited intensity modulated direct detected (IM-DD) systems [25,34-36]. DMT is a type of OFDM with real-valued output signals that can be easily detected with inexpensive direct detection receivers. As a multicarrier format, DMT also brings the flexibility of adapting the modulation format and power of any individual subcarrier to cope with the frequency dependence of the channel signal-to-noise ratio (SNR).

In this paper, we employ bit- and power-loaded DMT to show that the ASE spectrum-sliced scheme, the self-seeded RSOA-FCL, and the externally seeded RSOA configurations are viable US transmitters. The results are an expansion of our recent work [37], where only the maximized bit rates are presented. In this work, the SNR offered by each sources has been measured and compared. It is found that the SNR improves by more than $5 \mathrm{~dB}$ when switching from an ASE spectrum-sliced scheme to a self-seeded RSOA-FCL, and it improves by another $\sim 5 \mathrm{~dB}$ when switching from a self-seeded RSOA-FCL to an externally seeded RSOA. Finally, transmission experiments have been performed. We demonstrate 6.25, 20.1, and $30.7 \mathrm{Gbit} / \mathrm{s}$ in back-to-back (BtB) and 4.17, 10.1 and $24.5 \mathrm{Gbit} / \mathrm{s}$ over $25 \mathrm{~km}$ NZDSF (non-zero dispersion shifted fiber) for the ASE spectrum-sliced, RSOA-FCL and externally seeded RSOA sources, respectively. No offset filtering was needed in any of these experiments [14,25].

The organization of the paper is as follows. First, we discuss the steps for generating and analyzing a DMT signal. In Section 3, we present the experimental setups. In Section 4, we measure the SNR of the RSOA-FCL by varying WDM filter bandwidth, cavity length and bias current. We compare 
these results with the optimum SNR of the ASE spectrum-sliced and externally seeded RSOA schemes. Finally we present the results of bit- and power-loaded DMT transmission experiments.

\section{DMT Signal Generation and Reception}

DMT is a multi-carrier transmission technique with real-valued orthogonal subcarriers. The signal processing flow charts for a DMT transmitter and receiver are given in Figure 2. A pseudorandom bit sequence (PRBS) is generated to test the transmitter. The bits are then rearranged from serial into parallel according to the number of subcarriers and the information content in the respective subcarriers. Each parallel bit stream is then mapped onto its individual constellation (e.g., quadrature amplitude modulation-QAM). DMT gives us the flexibility to encode a different modulation format onto every subcarrier. Therefore, depending on the available SNR at each subcarrier the number of bits per symbol can be adapted to achieve the highest possible throughput, a feature called bit-loading. In our experiments, the modulation schemes ranged from binary phase shift keying (BPSK with $1 \mathrm{bit} / \mathrm{symbol}$ ) to 64QAM with $6 \mathrm{bit} / \mathrm{symbol}$. The constellation diagrams of the modulation formats are shown in Figure 3. After bit mapping, the power of each subcarrier is optimized in a power-loading stage depending on the SNR profile, see Figure 2. This is done such that all subcarriers will end up with a relatively similar bit error ratio (BER) performance even if they have different modulation formats. The adaptive bit-and power-loading algorithm is based on Chow's method discussed in [38]. In a next step, an inverse fast Fourier transform (IFFT) with Hermitian symmetry is performed to obtain the real valued DMT symbols. A cyclic prefix is added to each DMT symbol before being serialized and loaded into an arbitrary waveform generator (AWG). The AWG converts the DMT signal to the analog domain before it is fed to an RF amplifier and encoded to the optical domain by means of an RSOA.

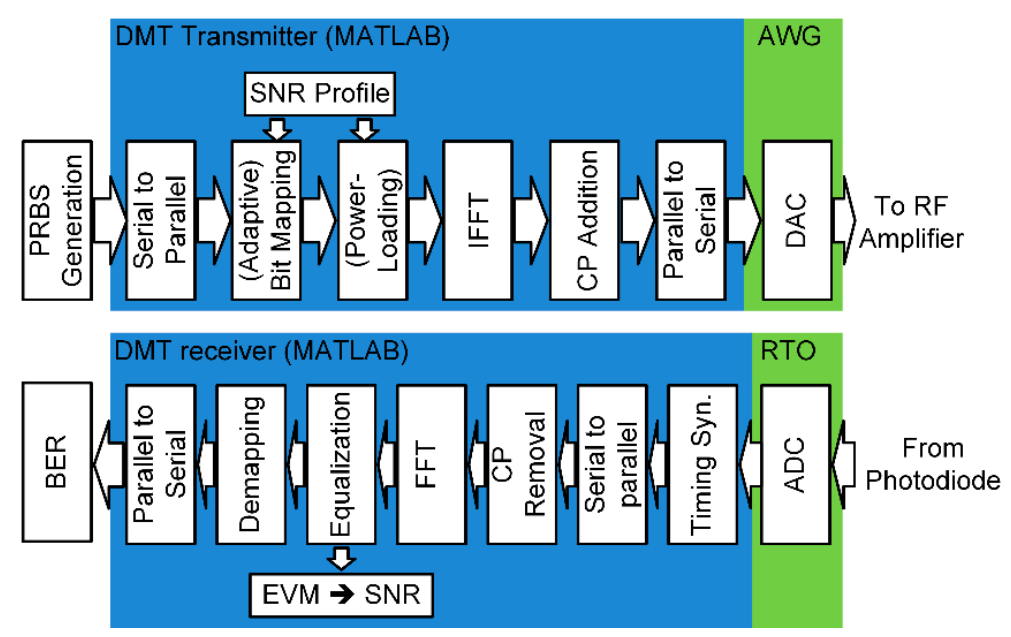

Figure 2. Discrete multi-tone (DMT) signal generation and reception flowchart. A pseudorandom bit sequence (PRBS) is generated, which is then rearranged into a parallel bit-stream. Subsequently, adaptive bit mapping and power-loading are implemented. Inverse fast Fourier transform (IFFT) is then used to encode the quadrature amplitude modulation (QAM) symbols on the DMT subcarriers. Cyclic prefix (CP) is added on the DMT symbols before the signal is converted back to serial. The serial data is loaded onto an arbitrary waveform generator (AWG) which converts the digital signal to analog using an inbuilt digital to analog converter (DAC). On the receiver side the signal is detected by a photodiode and sampled by a real-time oscilloscope (RTO).Next, timing synchronization is performed to recover the DMT clock. Then the serial signal is converted into a parallel data stream. After CP removal, FFT is used to decode the DMT subcarriers. Frequency and phase equalization of the received QAM symbols is performed. Here, we measure the error vector magnitude (EVM) and signal-to-noise ratio (SNR). Then, the symbols on each subcarrier are demapped to recover the transmitted PRBS for bit error ratio (BER) measurements. 


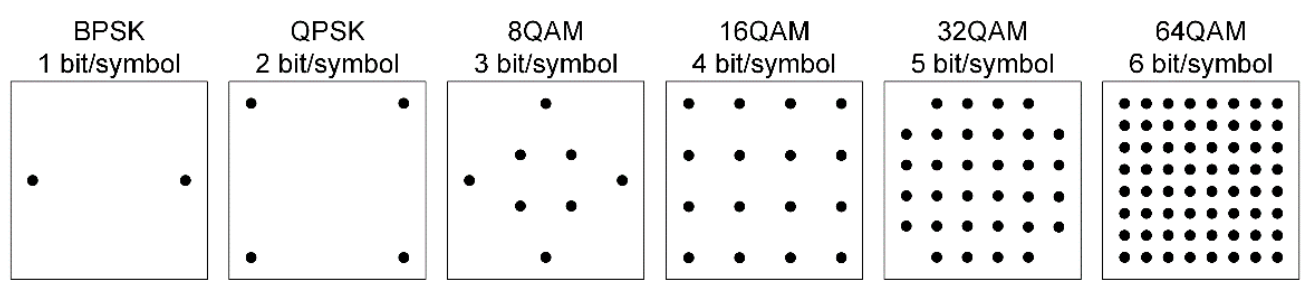

Figure 3. Constellation diagrams of modulation formats used for the bit- and power-loaded DMT signal generation. Binary phase shift keying (BPSK) encodes 1 bit/symbol. Quadrature phase shift keying (QPSK) encodes 2 bit/symbol. The quadrature amplitude modulation (QAM) formats: 8QAM, 16QAM, 32QAM, and 64QAM encode 3, 4, 5 and 6 bit/symbol, respectively.

In the receiver, a direct detection scheme is used to detect the optical signals. The electrical signals are then fed into a real-time oscilloscope (RTO). The RTO effectively digitizes the signal with a resolution of $\sim 5.8$ bits. In a first step, timing synchronization is performed using the non-data aided DMT timing estimation technique discussed in [39]. Subsequently, the signal is parallelized and the cyclic prefix is removed.The subcarriers within the electrical signal are then derived by the fast Fourier transform (FFT). To properly decode the bits within a subcarrier, blind phase and frequency offset estimation methods are applied on every subcarrier [40]. The error vector magnitude (EVM) of the QAM symbols on each subcarrier is calculated and converted into SNR [41]. Then, the QAM symbols are de-mapped to extract the received bit pattern. The BER is measured by comparing the transmitted and received bit patterns on each subcarrier. The overall BER is also measured by comparing the total transmitted and received bits.

\section{Experimental Setups}

In our experiments, we investigated the three colorless US transmitters in WDM-PON scenarios, see Figure 4. For all experiments, the transmitted DMT signal is generated offline with MATLAB and converted to an analog waveform by an AWG (Keysight M8195A-60 GSa/s, Santa Rosa, CA, USA). The analog signal is amplified and a DC bias current is added before being fed to an RSOA. In all cases, a $1 \mathrm{~mm}$ long InGaAsP quantum well C-band RSOA (provided by III-V labs, 10G-RSOA-11-S, Palaiseau, France) is placed at the ONU. The distribution fiber (DF) links the ONU to the RN. At the RN, a flat top optical band-pass filter (OBPF) emulates the WDM filter. RN and CO are connected by the feeder fiber (FF).

The three implementations of the RSOA based transmission links are shown in Figure 4 and described in more detailed now.

Figure 4a shows the setup for the ASE spectrum-sliced scheme. In this scheme, the current of an ROSA in the ONU is modulated with the data. This encodes the information onto the ASE output power of the RSOA. At the remote note, an OBPF (tuned to the emission center of the RSOA, which is at $1537.92 \mathrm{~nm}$ ) band limits the modulated ASE-signal to the assigned wavelength channel. The filtered signal is then sent to the CO. The filter bandwidth has been chosen to be identical to the filter bandwidth of the other schemes.

Figure $4 \mathrm{~b}$ shows the setup for the self-seeded RSOA-FCL. Here, a Faraday rotator (FR) is placed at ONU after the RSOA. In addition, a Faraday rotator mirror (FRM) is placed at the RN after a coupler behind the WDM filter. The FRM and the RSOA reflective facet form the Fabry-Perot resonator cavity embedded in the DF. In case of RSOA with high polarization dependent gain (HPDG), the FR and FRM cancel out the birefringence effect in the cavity and maintain a constant polarization at the RSOA input [42]. The coupler at the RN has a coupling ratio of $90 / 10$, where $90 \%$ of the power is kept in the cavity and $10 \%$ is transmitted to the CO. The large amount of the power kept in the cavity is required to overcome cavity losses and thereby to achieve a net gain and with this lasing. In addition, the high power in the cavity maintains the RSOA in the nonlinear operation region for better noise and residual modulation suppression $[17,43]$. 
Figure 4c shows the experimental setup for the externally seeded RSOA scheme. Here, a laser source (emitting at $1537.92 \mathrm{~nm}$, similar to the other setups) at the CO seeds the RSOA at the ONU through the fiber link. The seeding power entering the RSOA has been optimized for the highest SNR. The RSOA now only serves as a modulator and amplifier for the respective laser wavelength.
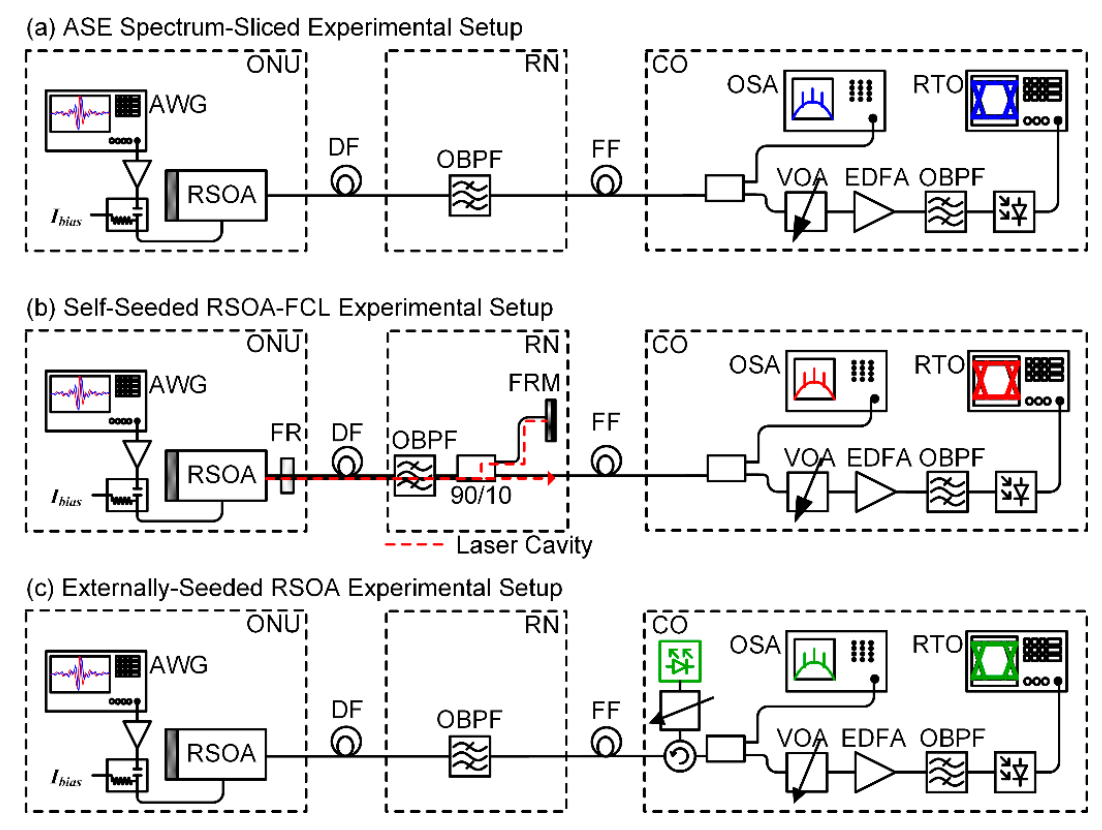

Figure 4. Experimental setups of three RSOA based colorless transmitter schemes in a WDM-PON scenario: (a) ASE spectrum-sliced, (b) self-seeded RSOA-FCL, and (c) externally seeded RSOA. At the optical network units (ONUs), the upstream signal from the arbitrary waveform generator (AWG) is amplified and added to a bias current to drive the RSOA. The ONU and the remote node (RN) are connected by the distribution fiber (DF). At the RN, an optical bandpass filter (OBPF) mimics the WDM filter. In the case of the RSOA-FCL in (b), the Faraday rotator mirror (FRM) is placed behind the filter and a coupler to form the Fabrey-Perot cavity, shown by the red dashed line. For the externally-seeded RSOA in (c), the seeding cw laser is place at the central office (CO). On the receiver side at the CO, pre-amplification and direct detection are performed. A real-time oscilloscope (RTO) records the electrical signal after the photodiode. An optical spectrum analyzer (OSA) is used to monitor the optical signal at the CO. EDFA: Erbium doped fiber amplifier, VOA: variable optical attenuator.

In the three schemes, we implement only a single optical channel measurement due to lack of equipment, however more than 16 channels have been demonstrated [2,21]. In all cases, the link budget between the $\mathrm{ONU}$ and the $\mathrm{CO}$ is $\sim 12 \mathrm{~dB}$ (i.e., combination of all insertion losses of components in the link between $\mathrm{ONU}$ and $\mathrm{CO}$ ). At the $\mathrm{CO}$, a direct detection receiver detects the signals from the three transmitters. Here, a $90 / 10$ coupler sends $10 \%$ of the power to an optical spectrum analyzer (OSA) to monitor the signal. A variable optical attenuator (VOA) is used to control the power entering the preamplifier Erbium doped fiber amplifier (EDFA). A pre-amplified direct detection receiver is used here to guarantee that the signal quality measured here is as much as possible independent of the receiver scheme. A $5 \mathrm{~nm}$ flat top OBPF suppresses the out of band ASE noise from the EDFA. The optical signal is finally detected by a photodiode (PIN, responsivity $0.6 \mathrm{~A} / \mathrm{W}$ ), which is directly connected to a RTO (DSOX96204Q-20 GHz bandwidth and $40 \mathrm{GSa} / \mathrm{s}$ ). The oscilloscope records the signal for offline post-processing with MATLAB as outlined in Figure 2.

\section{SNR Characterization}

In this section, we present the measured SNRs versus subcarrier frequency offered by the three transmitter schemes. Before presenting the results, we study the performance of the RSOA itself by 
measuring the electrical modulation bandwidth. In a second step, we then focus on the self-seeded RSOA-FCL. We study the impact of the WDM filter bandwidth in the RN, the fiber cavity length and the bias current on the SNR offered by the RSOA-FCL. Once the optimum operation parameters and limitations of the RSOA-FCL have been understood, we adjust the operation points of the ASE spectrum-sliced and the externally seeded RSOA. So for instance we set the WDM filter bandwidth of the ASE spectrum-sliced source to be identical with the RSOA-FCL. The input power for the externally seeded transmitters is also set for maximum performance. Here we only give the operation points that have been selected while one can find more details on finding the ideal operation points of an ASE spectrum-sliced transmitter in $[44,45]$ and the externally seeded transmitter $[25,46]$.

\subsection{Electrical Bandwidth of the RSOA}

We start our investigation by measuring the small signal modulation frequency response of the RSOA itself. We chose the externally seeded configuration to exclude the impact of dispersion and the external cavity. The frequency response for $50-120 \mathrm{~mA}$ bias current and at an input power of $-3 \mathrm{dBm}$ are plotted in Figure 5, which shows that the modulation response improves with higher bias current. At $100 \mathrm{~mA}$, the RSOA exhibits -3 and $-6 \mathrm{~dB}$ bandwidths of 2.4 and $4.55 \mathrm{GHz}$, respectively.

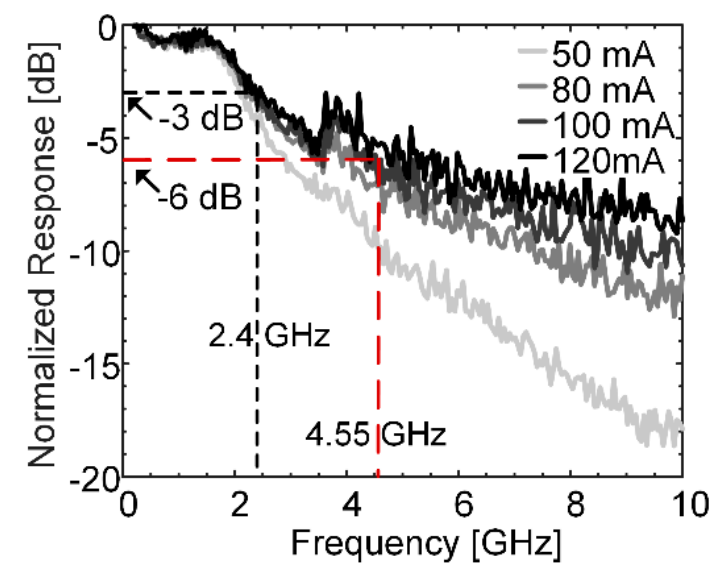

Figure 5. Measured small signal modulation frequency response of an RSOA at 50-120 mA bias currents. The modulation bandwidth increases with bias current. At $100 \mathrm{~mA}$, the RSOA has -3 and $-6 \mathrm{~dB}$ bandwidths of 2.4 and $4.55 \mathrm{GHz}$.

\subsection{RSOA-FCL Performance}

Here, we perform three studies to analyze the performance of the RSOA-FCL: First, we investigate the impact of the filter bandwidth in the cavity. Second, we study the SNR dependence on cavity length and bias current. Last, we explore the transmission performance for different cavity lengths at optimized operation conditions. In all cases, we use the SNR over the modulation frequency as a measure for the link performance and for comparing parameters.

The SNR over the modulation frequency is measured according to the following procedure. We transmit DMT signals and evaluate the SNR on each subcarrier at the receiver. Here, the modulation format and power of each subcarrier is identical. We generate a DMT signal having 256 subcarriers with QPSK as modulation format and equal electrical power for all subcarriers. A PRBS 11 is used as the transmitted bit sequence. The total symbol rate is $10 \mathrm{GBd}$. The IFFT size is 512 and a $2.5 \%$ cyclic prefix is added to each DMT symbol.

The signal is generated offline with MATLAB. An AWG generates the analog signal with $0.5 \mathrm{Vpp}$ (peak-to-peak voltage). The output of the RF amplifier was optimized to $3.5 \mathrm{Vpp}$. A bias tee combines the amplified signal with the specific bias current to drive the RSOA. On the receiver side, an RTO records the signal detected by a photodetector. Subsequently, the signal is demodulated in an offline 
digital signal processing step. The measured EVM of the subcarriers is used to calculate the SNR of each subcarrier. This way, we can determine the frequency resolved SNR of the transmission link across the whole modulation bandwidth. This allows us to determine the usable bandwidth of the transmission link. The useable bandwidth is the frequency band, within which the SNR is high enough to still allow for a BER below $10^{-3}$ with BPSK modulation. Theoretically, a minimum SNR of $6.7 \mathrm{~dB}$ is required.

First, we investigated the impact of the WDM filter bandwidth in the RN. We compared OBPF bandwidths of $0.6 \mathrm{~nm}$ and $2 \mathrm{~nm}$ for three cavity lengths of $15 \mathrm{~m}, 115 \mathrm{~m}$ and $1 \mathrm{~km}$ standard single mode fiber (SSMF). The bias current was maintained at $100 \mathrm{~mA}$. Figure 6 shows the SNR over the modulation frequency for both cases. The SNR is higher for the filter with wider bandwidth for all cavity lengths. For a $0.6 \mathrm{~nm}$ filter, the 15 and $115 \mathrm{~m}$ cavities have a peak SNRs of $\sim 14 \mathrm{~dB}$. The maximum SNR obtained for the $1 \mathrm{~km}$ cavity with $0.6 \mathrm{~nm}$ is only $\sim 12 \mathrm{~dB}$. The usable bandwidth of the $15,115 \mathrm{~m}$ and $1 \mathrm{~km}$ cavities with $0.6 \mathrm{~nm}$ filter was $\sim 4.6,4.5$ and $2.7 \mathrm{GHz}$. When a $2 \mathrm{~nm}$ filter has been used in the receiver one finds SNRs that are $5 \mathrm{~dB}$ higher. The usable bandwidth then increases by $\sim 40 \%$ to $\sim 6.7$, $\sim 6.4$ and $\sim 4.5 \mathrm{GHz}$. The results are summarized in Table 1 .

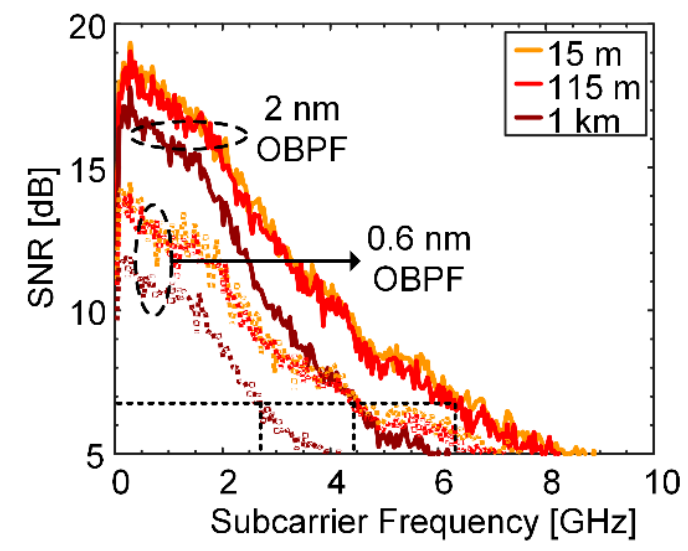

Figure 6. Measured SNR comparison of self-seeded RSOA-FCL transmitter with WDM filter bandwidths of 0.6 and $2 \mathrm{~nm}$ in RN. The dotted and solid lines show the measured SNR for the 0.6 and $2 \mathrm{~nm}$ filters, respectively. For both cases, three different cavity lengths, $15 \mathrm{~m}, 115 \mathrm{~m}$ and $1 \mathrm{~km}$ were used. $0.6 \mathrm{~nm}$ filter cavity has peak SNR which is $\sim 5 \mathrm{~dB}$ lower than that of the $2 \mathrm{~nm}$ one.

Table 1. Summary of results to compare the peak signal-to-noise ratio (SNR) and usable SNR bandwidth for the RSOA-FCL (reflective semiconductor optical amplifier fiber cavity laser) with $0.6 \mathrm{~nm}$ or $2 \mathrm{~nm}$ filter bandwidths. For both filters, the fiber cavity length varied between $15 \mathrm{~m}, 115 \mathrm{~m}$ and $1 \mathrm{~km}$. OBPF: optical band-pass filter.

\begin{tabular}{cccc}
\hline RSOA-FCL Cavity Length & OBPF $-\mathbf{3 ~ d B ~ B a n d w i d t h ~}$ & Peak SNR (dB) & Usable SNR Bandwidth (GHz) \\
\hline \multirow{2}{*}{$15 \mathrm{~m}$} & $0.6 \mathrm{~nm}$ & 14.3 & 4.6 \\
& $2 \mathrm{~nm}$ & 19.45 & 6.7 \\
\hline \multirow{2}{*}{$115 \mathrm{~m}$} & $0.6 \mathrm{~nm}$ & 14.1 & 4.5 \\
& $2 \mathrm{~nm}$ & 19.5 & 6.4 \\
\hline \multirow{2}{*}{$1 \mathrm{~km}$} & $0.6 \mathrm{~nm}$ & 11.9 & 2.7 \\
& $2 \mathrm{~nm}$ & 17.7 & 4.5 \\
\hline
\end{tabular}

One explanation for the SNR degradation with narrower filters would be that a narrower filter leads to higher losses [47]. For example, at $100 \mathrm{~mA}$, the reflected power into the RSOA was $\sim-6 \mathrm{dBm}$ and $\sim-2 \mathrm{dBm}$ for the 0.6 and $2 \mathrm{~nm}$ filters, respectively. Thus, higher losses means that the RSOA is less saturated. Therefore, the RSOA will be unable to efficiently suppress the residual modulation and noise. As a consequence the RIN will be higher and the SNR is degraded [47]. The second explanation based on [48] is that in case of highly multimode sources, increasing the number of modes (in this case 
wider filter) will distribute the noise over the multiple modes thus lowering the noise spectral density and RIN. Subsequently, we continue the investigation with the $2 \mathrm{~nm}$ filter only.

Next, we further investigated the impact of the distribution fiber cavity length and the bias current on the SNR of the self-seeded RSOA-FCL. We considered cavity lengths with $15 \mathrm{~m}, 115 \mathrm{~m}$ and $1 \mathrm{~km}$ SSMF to mimic WDM-PONs with distribution fibers in the range of tens of meters up to a few kilometers, for example in FTTA [49]. The RSOA bias current was set at 80, 100, 110 and $120 \mathrm{~mA}$. Figure 7a,b show similar performance for cavities with $15 \mathrm{~m}$ and $115 \mathrm{~m}$ length. The insets in Figure 7a,b which are the transmitted (black curve) and the received (red curve) DMT electrical spectrums also show similar characteristics. The similar performance originates from negligible chromatic dispersion for the two lengths. In both cases, the frequency dependent SNR increases with the bias current, which is related to the improved RSOA frequency response for higher bias currents as shown in Figure 5. The SNR degradation for higher modulation frequencies is due to the bandwidth limitations of the RSOA as discussed in Figure 5. At $110 \mathrm{~mA}$, both achieve maximum SNR of $\sim 19 \mathrm{~dB}$. The usable bandwidth where the SNR is still sufficiently high to receive a BPSK signal is $\sim 6.7$ and $\sim 6.4 \mathrm{GHz}$ for cavity lengths of $15 \mathrm{~m}$ and $115 \mathrm{~m}$, respectively.
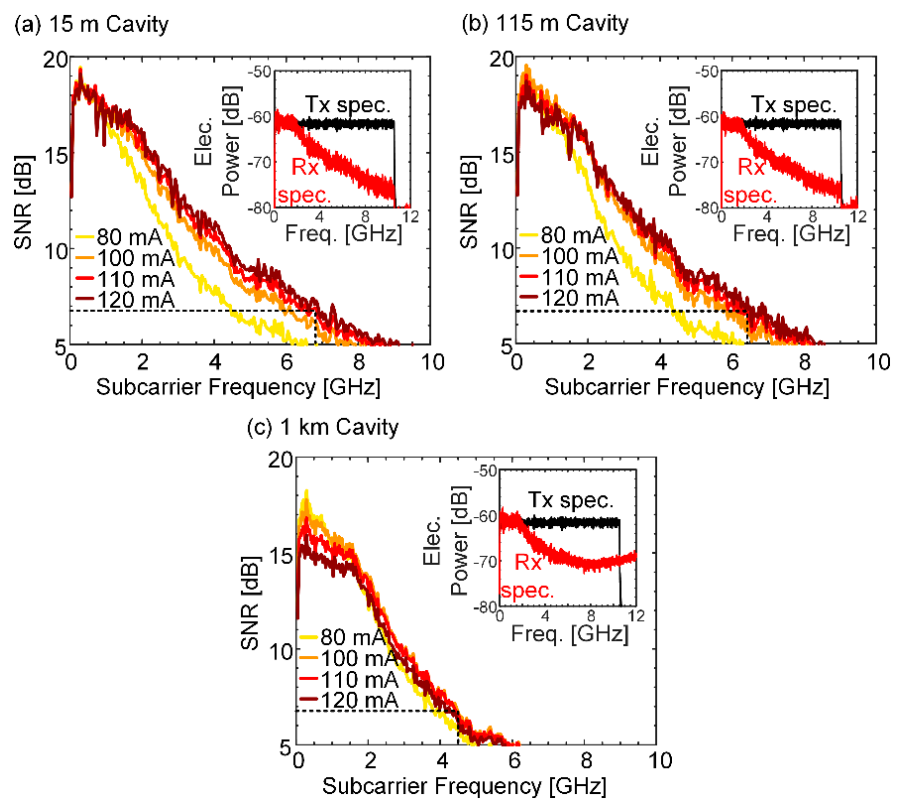

Figure 7. Measured SNR versus subcarrier frequency of self-seeded RSOA-FCLs operated at 80, 100, 110 and $120 \mathrm{~mA}$ bias currents for cavity lengths of (a) $15 \mathrm{~m}$, (b) $115 \mathrm{~m}$ and (c) $1 \mathrm{~km}$. The plots indicate that the SNR bandwidth generally increases with the bias current. The $1 \mathrm{~km}$ cavity shown in (c) has a reduced SNR peak and bandwidth when compared to the shorter cavities. The dashed line indicates the minimum SNR of $6.7 \mathrm{~dB}$ required to transmit BPSK, thus, it determines the usable bandwidth. In each plot, the insets show a sample electrical domain DMT spectra. The black and the red curves show the transmitted and received DMT electrical spectrum, respectively, at $110 \mathrm{~mA}$. The received DMT spectrum for the $1 \mathrm{~km}$ cavity RSOA-FCL shown in plot (c) inset has a higher noise level compared to that of the 15 and $115 \mathrm{~m}$ cavities spectra shown in insets of $(\mathbf{a}, \mathbf{b})$.

In Figure 7c we have plotted the SNR for the longer $1 \mathrm{~km} \mathrm{SSMF} \mathrm{cavity.} \mathrm{It} \mathrm{is} \mathrm{way} \mathrm{lower} \mathrm{than} \mathrm{those}$ in Figure $7 \mathrm{a}, \mathrm{b}$. This can be understood by the fact that total accumulated chromatic dispersion is larger. Since the RSOA-FCL is highly multi-mode, chromatic dispersion leads to considerable mode partition noise. This noise increases the RIN [50,51], causing a SNR degradation. A bit higher loss of the $1 \mathrm{~km}$ fiber cavity makes only a minor contribution to the SNR increase. At $110 \mathrm{~mA}$, the maximum SNR is $\sim 17 \mathrm{~dB}$ only and the usable bandwidth is now $\sim 4.5 \mathrm{GHz}$. In contrast to the RSOA-FCL with shorter cavity lengths, the SNR in the $1 \mathrm{~km}$ cavity is not increasing with bias current. We expect that this 
originates from the strong chirp during direct modulation at higher bias currents. The chirp causes spectral broadening which increases chromatic dispersion penalty. This induces an additional SNR degradation for higher bias currents [52]. This is supported by the large noise level in the received electrical DMT spectrum of the $1 \mathrm{~km}$ RSOA-FCL that can be seen in the inset of Figure 7c (red curve). However, the negative impact of the dispersive cavity on the SNR can be avoided by using O-band RSOAs. In the O-band where chromatic dispersion is minimum, RSOA-FCL cavity could be extended beyond $1 \mathrm{~km}[22,53]$.

Finally, we investigated the SNR after transmission over $25 \mathrm{~km}$ NZDSF (chromatic dispersion: $\sim 5 \mathrm{ps} / \mathrm{nm} \cdot \mathrm{km}$ ). This fiber is used to emulate a low dispersion PON fiber-similar to what one might expect if the system were operated in the O-Band. The probed SNR for the three cavity lengths for both a $\mathrm{BtB}$ and a $25 \mathrm{~km}$ transmission are plotted in Figure 8. When comparing the BtB and $25 \mathrm{~km}$ SNRs, the maximum SNR values for the respective cavity lengths did not show major change. Rather, the usable SNR bandwidth was reduced to $\sim 3.3,3.2$ and $2.8 \mathrm{GHz}$ for the $15 \mathrm{~m}, 115 \mathrm{~m}$ and $1 \mathrm{~km}$ cavities, respectively. The results are summarized in Table 2 . This shows a $40-50 \%$ bandwidth reduction compared to the BtB case. The finite signal bandwidth of the directly modulated RSOA results in chirp after propagation that induces power fading and bandwidth reduction. In addition, such highly multi-mode source suffers from mode partition noise induced by the NZDSF dispersion which increases the RIN.

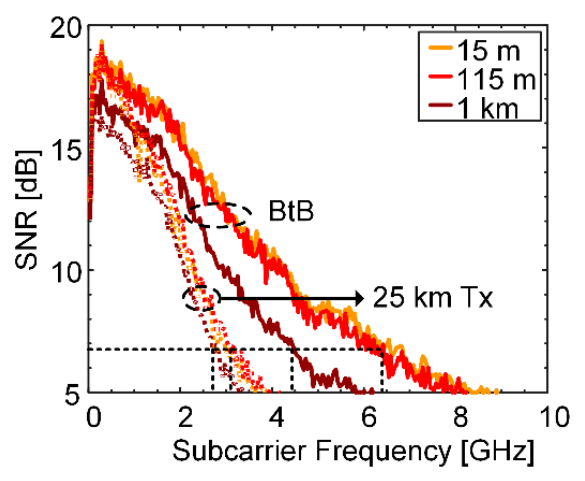

Figure 8. Measured SNR to compare the impact of transmission fiber on the performance of an RSOA-FCL: The solid and dotted lines show the measured SNR for BtB (back-to-back) and after $25 \mathrm{~km}$ non-zero dispersion shifted fiber (NZDSF) transmission, respectively. In both cases, the results are for $15 \mathrm{~m}, 115 \mathrm{~m}$ and $1 \mathrm{~km}$ fiber cavity lengths. The figure shows that the SNR bandwidth narrows by up to $50 \%$ after transmission over $25 \mathrm{~km}$ fiber.

Table 2. Summary of results for the SNR performance of the RSOA-FCL with $15 \mathrm{~m}, 115 \mathrm{~m}$ and $1 \mathrm{~km}$ cavities for back-to-back (BtB) and $25 \mathrm{~km}$ non-zero dispersion shifted fiber (NZDSF) transmission.

\begin{tabular}{cccc}
\hline RSOA-FCL Cavity Length & Tx & Peak SNR (dB) & Usable SNR Bandwidth (GHz) \\
\hline \multirow{2}{*}{$15 \mathrm{~m}$} & BtB & 19.45 & 6.7 \\
& $25 \mathrm{~km} \mathrm{NZDSF}$ & 19.01 & 3.2 \\
\hline \multirow{2}{*}{$115 \mathrm{~m}$} & BtB & 19.5 & 6.4 \\
& $25 \mathrm{~km} \mathrm{NZDSF}$ & 19.2 & 3.2 \\
\hline \multirow{2}{*}{$1 \mathrm{~km}$} & BtB & 17.7 & 4.5 \\
& $25 \mathrm{~km} \mathrm{NZDSF}$ & 17.1 & 2.8 \\
\hline
\end{tabular}

\subsection{Performance Comparison of the Three Transmitter Schemes}

Here, we compared the SNR performance of the ASE spectrum-sliced with the self-seeded RSOA-FCL and the externally seeded RSOA sources. For this experiment, the ASE spectrum-sliced source was equipped with the $2 \mathrm{~nm}$ filter, similar to that of the RSOA-FCL. For the RSOA-FCL, we took the $15 \mathrm{~m}$ and $1 \mathrm{~km}$ cavities, which offered the best and the worst performance, respectively. Both 
RSOA-FCLs were equipped with a $2 \mathrm{~nm}$ filter. The RSOA input and output power for the externally seeded scheme was $-3 \mathrm{dBm}$, and $\sim 6 \mathrm{dBm}$, respectively. The bias current for all experiments was set to $100 \mathrm{~mA}$. Figure 9a,b show the measured SNR values for BtB and transmission over $25 \mathrm{~km}$ NZDSF, respectively. It can be seen that the externally seeded RSOA and the self-seeded RSOA roughly offer a $10 \mathrm{~dB}$ and a $5 \mathrm{~dB}$ higher SNR over the ASE spectrum-sliced source across the whole spectral band. The self-seeded RSOA-FCL with the shorter cavity outperforms the longer cavity FCL by about 1-2 dB across the spectral band. And while the externally seeded RSOA exhibited the highest SNR bandwidth of $~ 9.6 \mathrm{GHz}$ for $\mathrm{BtB}$, the $15 \mathrm{~m}$ and $1 \mathrm{~km}$ long RSOA-FCLs offer useable bandwidths of 6.7 and $4.5 \mathrm{GHz}$ and the ASE spectrum-sliced scheme features a usable bandwidth of only $2.5 \mathrm{GHz}$.

(a) Back-to-back

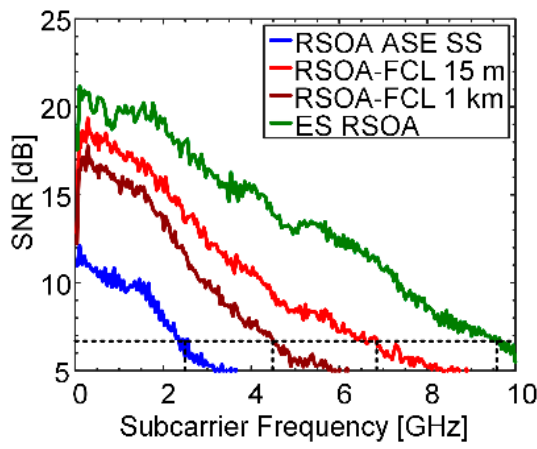

(b) $25 \mathrm{~km} \mathrm{Tx}$

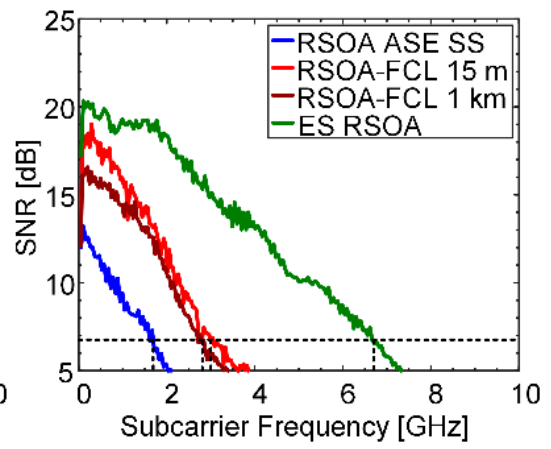

Figure 9. Comparison of the measured SNR for the three colorless transmitter schemes: RSOA ASE spectrum-sliced (SS), self-seeded RSOA-FCL and externally seeded (ES) RSOA. (a) Shows the BtB (back-to-back) SNR measurement. The externally seeded RSOA (green line) outperforms the RSOA-FCL (red and brown) and the ASE spectrum-sliced scheme (blue) by $~ 10$ and $~ 5 \mathrm{~dB}$ SNR across the whole frequency range, respectively; (b) Shows the SNR after $25 \mathrm{~km}$ NZDSF transmission. The SNR bandwidth is reduced due to dispersion of the transmission fiber. In general, the RSOA-FCL offers performance midway between an ASE spectrum sliced and an externally seeded RSOA.

When transmitting the signals over $25 \mathrm{~km}$ NZDSF fiber, the usable SNR bandwidth reduced to $\sim 1.6 \mathrm{GHz}$ for the ASE spectrum-sliced source. The RSOA-FCL declines to a usable bandwidths of 3 and $2.8 \mathrm{GHz}$ for the $15 \mathrm{~m}$ and $1 \mathrm{~km}$ long cavities. And the externally seeded RSOA still offers a $6.7 \mathrm{GHz}$ bandwidth with sufficient SNR for transmission. The source of the SNR degradation with transmission is the interplay of the chirp (induced by the direct modulation of the RSOA) and the dispersion of the transmission fiber. The narrower usable bandwidth recorded after transmission will influence the maximum achievable bit rate.

We attribute the higher performance observed for the RSOA-FCL when compared to the ASE spectrum-sliced source to three main factors. First, the RSOA-FCL has a significantly narrower spectrum, which significantly reduces the impact of chromatic dispersion [17,50]. Second, the RSOA-FCL has a larger output power. For example, at $100 \mathrm{~mA}$, the RSOA-FCL has an output power of $-3.4 \mathrm{dBm}$ while the ASE spectrum sliced scheme emits $-11.8 \mathrm{dBm}$. Third, the saturated RSOA in the cavity nonlinearly suppress the amplitude noise in the lasing cavity, which lowers the RIN. These three contribute to the improve SNR of the RSOA-FCL compared to the ASE spectrum sliced source [17].

\section{Bit- and Power-Loaded DMT for Highest Bit Rates}

In this section, bit- and power-loaded DMT transmission is used to maximize the data throughput for any of the three bandwidth limited sources. We proceed in two steps. We again first study the impact of the cavity length on the RSOA-FCL and the achievable data throughput in more detail. Only when we know the optimum operation conditions of the RSOA-FCL, we investigate and compare the maximum capacity of all three schemes. 


\subsection{Maximizing the Capacity of the RSOA-FCL}

In our experiments, we performed bit- and power-loading based on Chows algorithm [38]. Chow's algorithm can briefly be described as follows. It takes in the SNR characterization of a transmitter at the subcarrier frequencies of the DMT signal. It also uses the SNR requirement of all advanced modulation formats (see Figure 3) to achieve a predetermined BER. Then, it disregards subcarriers with the lowest SNR that cannot support transmission at the predetermined BER for even the simplest format. The power of such unusable subcarriers is then transferred to usable subcarriers. For subcarrier with non-integer bit per symbol, the bit number is rounded off to the nearest integer, which requires the power to be re-adapted accordingly. This power adaptation step (power-loading) helps to achieve similar BER for all subcarriers.

First, we performed bit- and power-loaded DMT transmission for the RSOA-FCL with $15 \mathrm{~m}$, $115 \mathrm{~m}$ and $1 \mathrm{~km}$ cavities. The signal was optimized for a BtB experiment and for transmission over $25 \mathrm{~km}$ NZDSF. Figure 10a-c show the SNR, and the bit- as well as the power-loading patterns of the DMT and the measured per-subcarrier BER for $15 \mathrm{~m}, 115 \mathrm{~m}$ and $1 \mathrm{~km}$ long RSOA-FCLs, respectively. The 15 and $115 \mathrm{~m}$ cavities can support up to $5 \mathrm{bit} / \mathrm{symbol}$ (32QAM) for low frequency subcarriers. In case of the $1 \mathrm{~km}$ RSOA-FCL, the highest order modulation format is 16QAM, with 4 bits/symbol. The power-loading pattern is arranged to guarantee a minimum SNR difference for all subcarriers with the same modulation format, so that a similar BER performance can be obtained. The solid lines in the BER plots indicate the overall BER, i.e., the total BER across all subcarriers. It can be seen that the overall BER is below $9.29 \times 10^{-3}$ in all instances, which is the limit for an FEC (forward error correction) with $12.5 \%$ overhead [54].

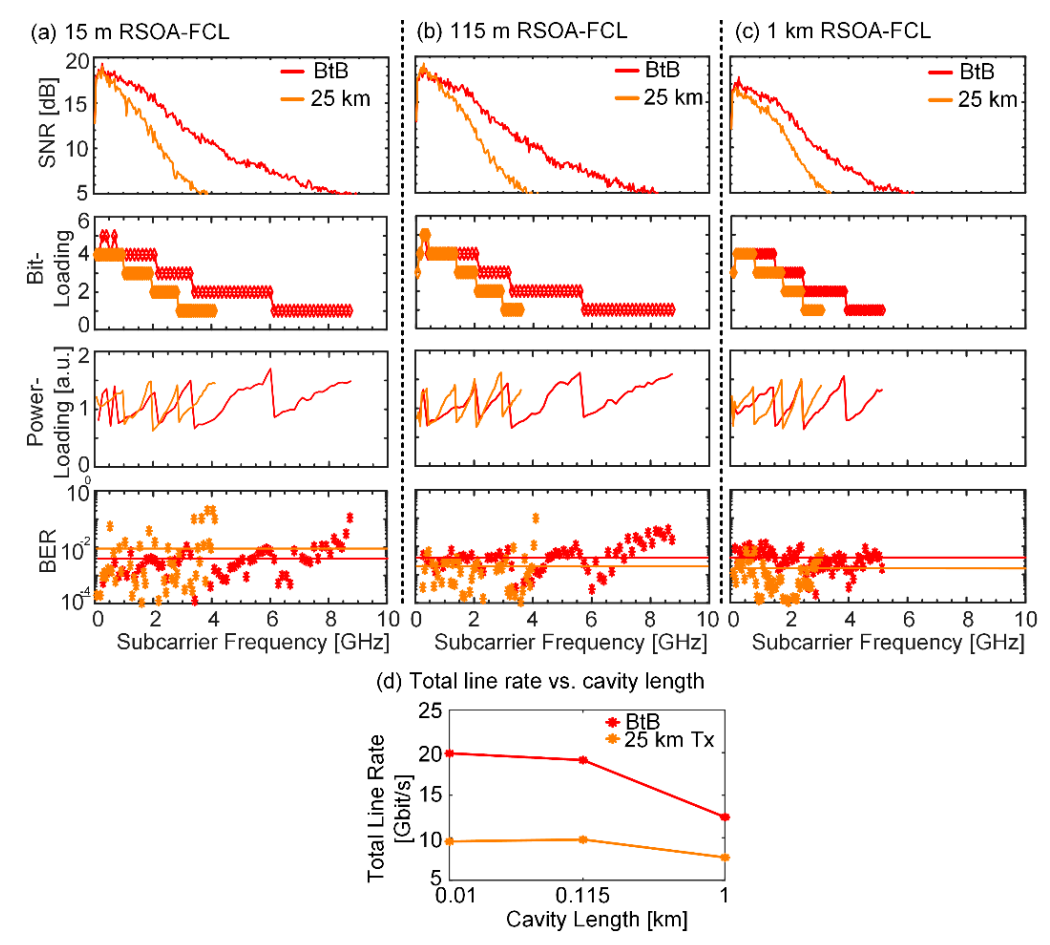

Figure 10. Measured SNR, bit- and power-loading pattern, and bit error ratio (BER) versus sub-carrier frequencies and the achieved total line rate for different RSOA-FCL cavity lengths: Plots $(\mathbf{a}-\mathbf{c})$ show the results for 15, $115 \mathrm{~m}$ and $1 \mathrm{~km}$ long cavities, respectively. The red and orange colors indicate $\mathrm{BtB}$ (back-to-back) and $25 \mathrm{~km}$ NZDSF transmission measurements. In all cases, the overall BER (solid lines in the BER plots) are kept below the FEC limit of $9.29 \times 10^{-3}$ [53]; (d) Plots the measured total line rate for $15,115 \mathrm{~m}$ and $1 \mathrm{~km}$ long cavities, both for BtB and after $25 \mathrm{~km}$ transmission. In a BtB measurement, the RSOA-FCL offers up to $20 \mathrm{Gbit} / \mathrm{s}$ line rates. The line-rate is still $10 \mathrm{Gbit} / \mathrm{s}$ when transmitting signals over $25 \mathrm{~km}$. 
Figure $10 \mathrm{~d}$ shows the maximum line rates obtained with RSOA-FCL cavity lengths of $15 \mathrm{~m}, 115 \mathrm{~m}$ and $1 \mathrm{~km}$ length for a BtB and a transmission over $25 \mathrm{~km}$ NZDSF. Maximum capacities are obtained for short FCL cavities of 15 and $115 \mathrm{~m}$ length. The capacities are between 20 and $10 \mathrm{Gbit} / \mathrm{s}$ depending on the transmission distance. For longer cavity lengths the capacity dropped to $12.4 \mathrm{Gbit} / \mathrm{s}$ due to a reduced SNR and a limited bandwidth for the BtB experiment and $7 \mathrm{Gbit} / \mathrm{s}$ could at best be transmitted over $25 \mathrm{~km}$.

\subsection{Comparison of Maximizing Capacity}

Second, we compared the maximum capacity achievable with bit- and power-loaded ASE spectrum-sliced, two types of self-seeded FCL RSOAs and externally seeded RSOAs.

Figure 11a,b show BtB and $25 \mathrm{~km}$ DMT transmission results, respectively. For low subcarrier frequencies, the ASE spectrum-sliced source supported up to $3 \mathrm{bit} /$ symbol (8QAM), the RSOA-FCL up to $5 \mathrm{bit} / \mathrm{symbol}$ (32QAM), and the externally seeded RSOA up to $6 \mathrm{bit} / \mathrm{symbol}$ (64QAM). The power-loading pattern shown in Figure 11a,b led to relatively similar SNRs for subcarriers with the same modulation format. As a result, the BER for different subcarriers was relatively constant over the modulation frequency. The solid lines show the overall BER. For all schemes, the overall BERs were kept below $7.5 \times 10^{-3}(10 \%$ overhead FEC) [54].

(a) Back-to-back
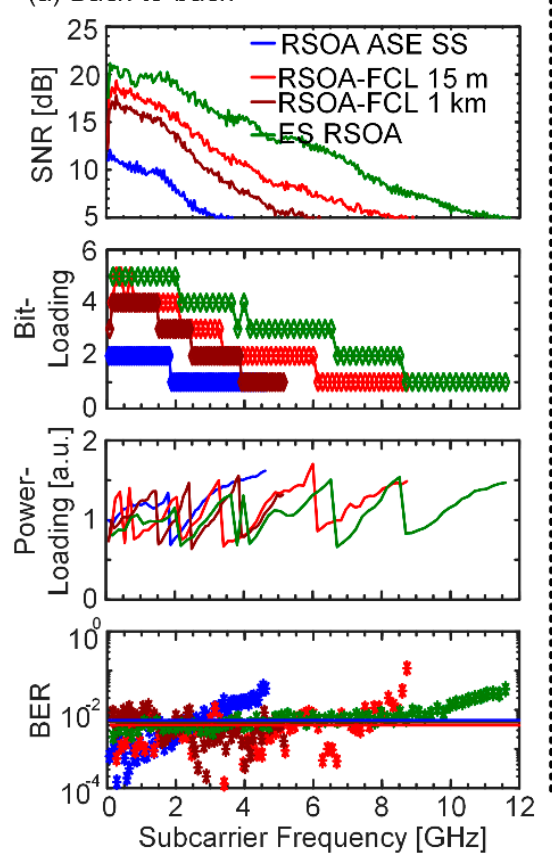

(b) $25 \mathrm{~km}$

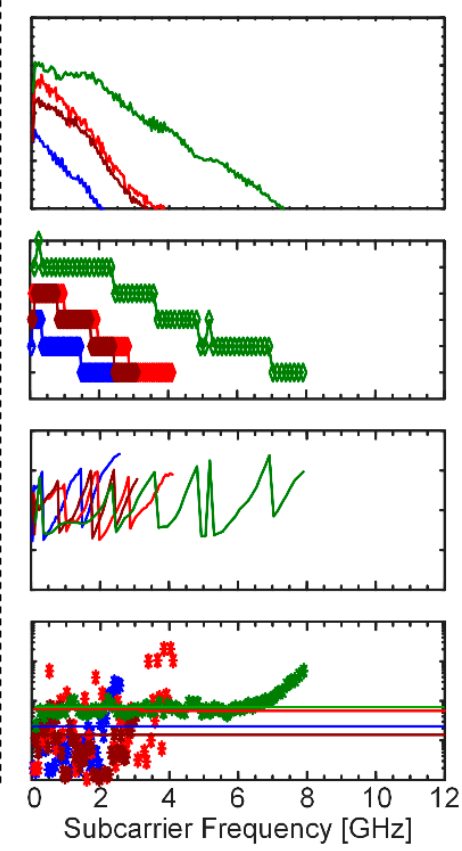

Figure 11. Measured SNR, bit- and power-loading pattern and per-subcarrier BER for the three transmitter schemes: RSOA ASE spectrum-sliced (SS) (blue), self-seeded RSOA-FCL (red and brown) and externally seeded (ES) RSOA (green). (a) and (b) show results for back to back case and $25 \mathrm{~km}$ transmission. The ASE spectrum sliced scheme can support modulation formats with up to 3 bits /symbol while RSOA-FCL and externally seeded RSOA can encode up to 6 bits/symbol for low subcarrier frequencies. The solid line in the bottom plot indicates the overall BER that can be achieved with either of the three transmission schemes. All bit-error ratios are within the FEC (forward error correctio) limit of $7.5 \times 10^{-3}$.

Table 3 summarizes the achieved maximum line rates for the three transmitter schemes and the corresponding overall BER. In a BtB experiment the ASE spectrum-sliced, the RSOA-FCL and the externally seeded sources were delivering capacities up to $6.25,20.1$ and $30.7 \mathrm{Gbit} / \mathrm{s}$, respectively. For a link with $25 \mathrm{~km}$ the sources could still deliver maximum capacities of 4.2, 10.1 and $24.5 \mathrm{Gbit} / \mathrm{s}$. 
It is interesting to note that the chirp-dispersion induced usable bandwidth reduction results in considerable capacity reduction, especially in the case of the ASE spectrum-sliced and RSOA-FCL transmitters. This can be explained by the relatively wider linewidth of the two sources, thus incurring higher dispersion penalty. However, O-band RSOAs [53], can be used to lower dispersion penalty and avoid the need for NZDSF. O-band has already been used for upstream transmission in legacy PONs to relax the requirement on inexpensive poor sources $[1,55]$.

Table 3. Summary of achieved line rate and the respective bit error ratio (BER) for the three transmitter schemes. The results are for a BtB (back-to-back) and after $25 \mathrm{~km}$ NZDSF transmission. ASE: amplified spontaneous emitters.

\begin{tabular}{ccccccccc}
\hline & \multicolumn{2}{c}{ ASE Spectrum-Sliced } & \multicolumn{2}{c}{ RSOA-FCL $\mathbf{( 1 5} \mathbf{~ m )}$} & \multicolumn{2}{c}{ RSOA-FCL $\mathbf{~ ( 1 ~ k m ) ~}$} & \multicolumn{2}{c}{ Externally Seeded RSOA } \\
\cline { 2 - 9 } & $\begin{array}{c}\text { Line Rate } \\
\text { (Gbit/s) }\end{array}$ & BER & $\begin{array}{c}\text { Line Rate } \\
\text { (Gbit/s) }\end{array}$ & BER & $\begin{array}{c}\text { Line Rate } \\
\text { (Gbit/s) }\end{array}$ & BER & $\begin{array}{c}\text { Line Rate } \\
\text { (Gbit/s) }\end{array}$ & BER \\
\hline BtB & 6.25 & $5.8 \times 10^{-3}$ & 20.1 & $5.8 \times 10^{-3}$ & 12.4 & $5.8 \times 10^{-3}$ & 30.7 & $5.7 \times 10^{-3}$ \\
$25 \mathrm{~km} \mathrm{NZDSF}$ & 4.2 & $2.3 \times 10^{-3}$ & 10.1 & $4 \times 10^{-3}$ & 7 & $5.8 \times 10^{-3}$ & 24.5 & $7.1 \times 10^{-3}$ \\
\hline
\end{tabular}

\section{Conclusions}

We show how transmission capacities of low-cost low-quality sources can be optimized for maximum capacities by means of bit- and power-loaded DMT transmission. Record high transmission data rates for an ASE spectrum-sliced, self-seeded RSOA-FCL and externally seeded RSOA of 6.25, 20 and $30.7 \mathrm{Gbit} / \mathrm{s}$ in BtB and 4.2, 12.4 and $24.5 \mathrm{Gbit} / \mathrm{s}$ over $25 \mathrm{~km}$ NZDSF transmission are reported. To the best of our knowledge, these are the highest capacities reported for such inexpensive and colorless sources. Our experiments show that even lowest cost sources such as spectral sliced ASE sources or RSOA-FCLs can offer quite some capacity if properly operated, for example, for O-band upstream transmission. More precisely, ASE sources can provide capacities in the range of 6 to $4 \mathrm{Gbit} / \mathrm{s}$ depending on the distance. Fabry-Perot sources such as the RSOA-FCL may offer capacities in the order of 20 to $10 \mathrm{Gbit} / \mathrm{s}$ for distances up to $25 \mathrm{~km}$. Finally, more costly externally seeded colorless sources may provide capacities in the range of 30 to $25 \mathrm{Gbit} / \mathrm{s}$ if operated with an optimized bit- and power loaded DMT transmission format without offset filtering.

Acknowledgments: This work was supported by the EU FP7 projects ERMES (grant agreement no. 288542) and Fox-C (grant agreement No. 318415). Sterlite Technologies Ltd. is acknowledged for providing the fiber.

Author Contributions: Simon Arega Gebrewold conceived the concept, designed and performed the experiments, carried out the signal processing and analysis and wrote the paper. Romain Bonjour contributed in the concept development, experiment and manuscript writing. Romain Brenot designed and fabricated the RSOAs. David Hillerkuss organized the experiment and wrote the paper. Juerg Leuthold conceived and developed the concept, designed the experiment, wrote the paper and supervised the work.

Conflicts of Interest: The authors declare no conflict of interest.

\section{References}

1. Effenberger, F.J.; Mukai, H.; Park, S.; Pfeiffer, T. Next-generation PON-part II: Candidate systems for next-generation PON. IEEE Commun. Mag. 2009, 47, 50-57. [CrossRef]

2. Vetter, P. Next generation optical access technologies. In Proceedings of the European Conference and Exhibition on Optical Communication, Amsterdam, The Netherlands, 16-20 September 2012; Tu.3.G.1.

3. Pfeiffer, T. Next Generation Mobile Fronthaul and Midhaul Architectures [Invited]. J. Opt. Commun. Netw. 2015, 7, 38-45. [CrossRef]

4. Saliou, F.; Gael, S.; Chanclou, P.; Pizzinat, A.; Lin, H.; Zhou, E.; Xu, Z. WDM PONs Based on Colorless Technology. Opt. Fiber Technol. 2015, 26, 126-134. [CrossRef]

5. Woodward, S.L.; Iannone, P.P.; Reichmann, K.C.; Frigo, N.J. A spectrally Sliced PON Employing Fabry-Perot lasers. IEEE Photonics Technol. Lett. 1998, 10, 1337-1339. [CrossRef]

6. Frigo, N.J. Recent Progress in Optical Access Networks. In Proceedings of the Optical Fiber Communications, San Jose, CA, USA, 25 February-1 March 1996; pp. 142-143. 
7. Payoux, F.; Chanclou, P.; Genay, N. WDM-PON with Colorless ONUs. In Proceedings of the Optical Fiber Communication Conference and Exposition and the National Fiber Optic Engineers Conference, Anaheim, CA, USA, 25 March 2007.

8. Horiuchi, Y. Economical Solutions of the WDM-PON System. In Proceedings of the Optical Fiber Communication Conference, Los Angeles, CA, USA, 4-8 March 2012; pp. 1-3.

9. Healey, P.; Townsend, P.; Ford, C.; Johnston, L.; Townley, P.; Lealman, I.; Rivers, L.; Perrin, S.; Moore, R. Spectral Slicing WDM-PON Using Wavelength-Seeded Reflective SOAs. Electron. Lett. 2001, 37, 1181-1182. [CrossRef]

10. Han, K.H.; Son, E.S.; Choi, H.Y.; Lim, K.W.; Chung, Y.C. Bidirectional WDM PON using Light-Emitting Diodes Spectrum-Sliced with Cyclic Arrayed-Waveguide Grating. IEEE Photonics Technol. Lett. 2004, 16, 2380-2382. [CrossRef]

11. Arellano, C.; Polo, V.; Bock, C.; Prat, J. Bidirectional Single Fiber Transmission Based on a RSOA ONU for FTTH Using FSK-IM Modulation Formats. In Proceedings of the Optical Fiber Communication Conference, Anaheim, CA, USA, 6-11 March 2005; JWA46.

12. Buset, J.M.; El-Sahn, Z.A.; Plant, D.V. Experimental Demonstration of a 10 Gb/s RSOA-based 16-QAM Subcarrier Multiplexed WDM PON. Opt. Express 2014, 22, 1-8. [CrossRef] [PubMed]

13. Wei, J.L.; Hugues-Salas, E.; Giddings, R.P.; Jin, X.Q.; Zheng, X.; Mansoor, S.; Tang, J.M. Wavelength Reused Bidirectional Transmission of Adaptively Modulated Optical OFDM Signals in WDM-PONs Incorporating SOA and RSOA Intensity Modulators. Opt. Express 2010, 18, 9791-9808. [CrossRef] [PubMed]

14. Presi, M.; Cossu, G.; Chiuchiarelli, A.; Bottoni, F.; Corsini, R.; Choudhury, P.; Giorgi, L.; Ciaramella, E. $25 \mathrm{~Gb} / \mathrm{s}$ Operation of 1-GHz Bandwidth R-SOA by using DMT and Optical Equalization. In Proceedings of the Optical Fiber Communication Conference and Exposition and the National Fiber Optic Engineers Conference, Anaheim, CA, USA, 17-21 March 2013; OW1A.7.

15. De Valicourt, G.; Maké, D.; Landreau, J.; Lamponi, M.; Duan, G.H.; Chanclou, P.; Brenot, R. High Gain (30 dB) and High Saturation Power $(11 \mathrm{dBm})$ RSOA Devices as Colorless ONU Sources in Long-Reach Hybrid WDM/TDM-PON Architecture. IEEE Photonics Technol. Lett. 2010, 22, 191-193. [CrossRef]

16. Lin, G.R.; Liao, Y.S.; Chi, Y.C.; Kua, H.C.; Lin, G.C.; Wang, H.L.; Chen, Y.J. Long-Cavity Fabrey-Perot Laser Amplifier Transmitter with Enhanced Injection-Locking Bandwidth for WDM-PON Application. J. Lightwave Technol. 2010, 28, 2925-2932. [CrossRef]

17. Gebrewold, S.A.; Bonjour, R.; Barbet, S.; Maho, A.; Brenot, R.; Chanclou, P.; Brunero, M.; Marazzi, L.; Parolari, P.; Totovic, A.; et al. Self-Seeded RSOA-Fiber Cavity Lasers vs. ASE Spectrum-Sliced or Externally Seeded Transmitters-A Comparative Study. Appl. Sci. 2015, 5, 1922-1941. [CrossRef]

18. Sung-Bum, P.; Dae Kwang, J.; Dong, J.S.; Hong, S.S.; Yun, I.K.; Jeong, S.L.; Yun, K.O.; Yun, J.O. Colorless Operation of WDM-PON Employing Uncooled Spectrum-Sliced RSOA. IEEE Photonics Technol. Lett. 2007, 19, 248-250.

19. Henning, L.F.; Monteiro, P.; Almeida, A.D.; Pohl, P. Comparison of LED and RSOA performance in WDM-PONs. In Proceedings of the 21st International Conference on Telecommunications, Lisbon, Portugal, 4-7 May 2014; pp. 124-128.

20. Wong, E.; Lee, K.L.; Anderson, T.B. Directly Modulated Self-Seeding Reflective Semiconductor Optical Amplifiers as Colorless Transmitters in Wavelength Division Multiplexed Passive Optical Networks. J. Lightwave Technol. 2007, 25, 67-74. [CrossRef]

21. Marazzi, L.; Parolari, P.; Brenot, R.; De Valicourt, G.; Martinelli, M. Network-embedded self-tuning cavity for WDM-PON transmitter. Opt. Express 2012, 20, 3781-3786. [CrossRef] [PubMed]

22. Maho, A.; Gael, S.; Barbet, S.; Francois, L.; Saliou, F.; Chanclou, P.; Parolari, P.; Marazzi, L.; Brunero, M.; Martinelli, M.; et al. Demystification of the Self-Seeded WDM Access. J. Lightwave Technol. 2015, 34, 776-782. [CrossRef]

23. Le, S.D.; Lebreton, A.; Saliou, F.; Deniel, Q.; Charbonier, B.; Chanclou, P. Up to $60 \mathrm{~km}$ Bidirectional Transmission of a 16 Channels $\times 10$ Gb/s FDM-WDM PON Based on Self-Seeded Reflective Semiconductor Optical Amplifiers. In Proceedings of the Optical Fiber Communications Conference and Exhibition (OFC), San Francisco, CA, USA, 9-13 March 2014; Th3G.8.

24. Shim, H.; Kim, H.; Chung, Y.C. 20-Gb/s Operation of RSOA using Polar Return-to-Zero 4-PAM Modulation Format and Direct Detection. In Proceedings of the Optical Fiber Communication Conference, Los Angeles, CA, USA, 22-26 March 2015; W1J.2. 
25. Cossu, G.; Bottoni, F.; Corsini, R.; Presi, M.; Ciaramella, E. 40 Gb/s Single R-SOA Transmission by Optical Equalization and Adaptive OFDM. IEEE Photonics Technol. Lett. 2013, 25, 2119-2122. [CrossRef]

26. De Valicourt, G.; Make, D.; Fortin, C.; Enard, A.; Van-Dijk, F.; Brenot, R. 10 Gbit/s Modulation of RSOA without any Electronic Processing. In Proceedings of the Optical Fiber Communication Conference/National Fiber Optic Engineers Conference, Los Angeles, CA, USA, 6-10 March 2011; OThT2.

27. Cho, K.Y.; Takushima, Y.; Chung, Y.C. 10-Gb/s Operation of RSOA for WDM PON. IEEE Photonics Technol. Lett. 2008, 20, 1533-1535. [CrossRef]

28. Hoon, K. 10-Gb/s Operation of RSOA Using a Delay Interferometer. IEEE Photonics Technol. Lett. 2010, 22, 1379-1381.

29. Torrientes, D.; Chanclou, P.; Laurent, F.; Tsyier, S.; Chang, Y.F.; Charbonnier, B.; Raharimanitra, F. RSOA-Based 10.3 Gbit/s WDM-PON with Pre-Amplification and Electronic Equalization. In Proceedings of the Optical Fiber Communication Conference, Los Angeles, CA, USA, 21-25 March 2010; JThA28.

30. Papagiannakis, I.; Omella, M.; Klonidis, D.; Birbas, A.N.; Kikidis, J.; Tomkos, I.; Prat, J. Investigation of 10-Gb/s RSOA-Based Upstream Transmission in WDM-PONs Utilizing Optical Filtering and Electronic Equalization. IEEE Photonics Technol. Lett. 2008, 20, 2168-2170. [CrossRef]

31. Cho, K.Y.; Chung, Y.C. 10-Gb/s Operation of RSOA for WDM PON Using Return-to-Zero Modulation Format. In Proceedings of the Optical Fiber Communication Conference and Exposition (OFC/NFOEC), Los Angeles, CA, USA, 4-8 March 2012; OTh1F.2.

32. Hyun Kyu, S.; Hoon, K.; Yun, C.C. 20-Gb/s Polar RZ 4-PAM Transmission over 20-km SSMF Using RSOA and Direct Detection. IEEE Photonics Technol. Lett. 2015, 27, 1116-1119.

33. Zhang, Q.W.; Hugues-Salas, E.; Ling, Y.; Zhang, H.B.; Giddings, R.P.; Zhang, J.J.; Wang, M.; Tang, J.M. Record-high and robust $17.125 \mathrm{~Gb} / \mathrm{s}$ gross-rateover $25 \mathrm{~km}$ SSMF transmissions of real-time dual-band optical OFDM signals directly modulated by 1 GHz RSOAs. Opt. Express 2014, 22, 6339-6348. [CrossRef] [PubMed]

34. Xie, C.; Dong, P.; Randel, S.; Winzer, P.; Spiga, S.; Koegel, B.; Neumeyr, C.; Amann, M.C. Single-VCSEL 100-Gb/s Short-Reach System Using Discrete Multi-Tone Modulation and Direct Detection. In Proceedings of the Optical Fiber Communications Conference and Exhibition (OFC), Los Angeles, CA, USA, 22-26 March 2015; pp. 1-3.

35. Takahara, T.; Tanaka, T.; Nishihara, M.; Kai, Y.; Li, L.; Tao, Z. Discrete Multi-Tone for 100 Gb/s Optical Access Networks. In Proceedings of the Optical Fiber Communication Conference, San Francisco, CA, USA, 9-13 March 2014; M2l.1.

36. Nadal, L.; Moreolo, M.S.; Fabrega, J.M.; Dochhan, A.; Griesser, H.; Eiselt, M.; Elbers, J.P. DMT Modulation With Adaptive Loading for High Bit Rate Transmission Over Directly Detected Optical Channels. J. Lightwave Technol. 2014, 32, 4143-4153. [CrossRef]

37. Gebrewold, S.A.; Brenot, R.; Bonjour, R.; Josten, A.; Baeuerle, B.; Hillerkuss, D.; Hafner, C.; Leuthold, J. Colorless Low-Cost RSOA Based Transmitters Optimized for Highest Capacity Through Bit- and Power-Loaded DMT. In Proceedings of the Optical Fiber Communication Conference, Anaheim, CA, USA, 20-22 March 2016; Tu2C.4.

38. Chow, P.S.; Cioffi, J.M.; Bingham, J.A. A practical Discrete Multitone Transceiver Loading Algorithm for Data Transmission over Spectrally Shaped Channels. IEEE Trans. Commun. 1995, 43, 773-775. [CrossRef]

39. Pollet, T.; Peeters, M. Synchronization with DMT modulation. IEEE Commun. Mag. 1999, 37, 80-86. [CrossRef]

40. Nakagawa, T.; Kobayashi, T.; Ishihara, K.; Miyamoto, Y. Non-Data-Aided Wide-Range Frequency Offset Estimator for QAM Optical Coherent Receivers. In Proceedings of the Optical Fiber Communication Conference/National Fiber Optic Engineers Conference, Los Angeles, CA, USA, 6-10 March 2011; OMJ1.

41. Schmogrow, R.; Nebendahl, B.; Winter, M.; Josten, A.; Hillerkuss, D.; Koenig, S.; Meyer, J.; Dreschmann, M.; Huebner, M.; Koos, C.; et al. EVM as a Performance Measure for Advanced Modulation Formats. IEEE Photonics Technol. Lett. 2012, 24, 61-63. [CrossRef]

42. Martinelli, M.; Marazzi, L.; Parolari, P.; Brunero, M.; Gavioli, G. Polarization in Retracing Circuits for WDM-PON. IEEE Photonics Technol. Lett. 2012, 24, 1191-1193. [CrossRef]

43. Marazzi, L.; Parolari, P.; Boletti, A.; Gatto, A.; Martinelli, M.; Brrnot, R. Highly-nonlinear RSOA RIN compression. In Proceedings of the 19th European Conference on Networks and Optical Communications, Milano, Italy, 4-6 June 2014; pp. 115-119. 
44. Kani, J.; Kawata, H.; Iwatsuki, K.; Ohki, A.; Sugo, M. Design and Demonstration of Gigabit Spectrum-Sliced WDM Systems Employing Directly Modulated Super Luminescent Diodes. In Proceedings of the Optical Fiber Communication Conference and Exposition and the National Fiber Optic Engineers Conference, Anaheim, CA, USA, 6-11 March 2005; JWA49.

45. Pendock, G.J.; Sampson, D.D. Transmission performance of high bit rate spectrum-sliced WDM systems. J. Lightwave Technol. 1996, 14, 2141-2148. [CrossRef]

46. Wei, J.L.; Hamie, A.; Gidding, R.P.; Hugues-Salas, E.; Zheng, X.; Mansoor, S.; Tang, J.M. Adaptively Modulated Optical OFDM Modems Utilizing RSOAs as Intensity Modulators in IMDD SMF Transmission Systems. Opt. Express 2010, 18, 8556-8573. [CrossRef] [PubMed]

47. Marazzi, L.; Parolari, P.; Brunero, M.; Gatto, A.; Martinelli, M.; Brenot, R.; Barbet, S.; Galli, P.; Gavioli, G. Up to 10.7-Gb/s High-PDG RSOA-Based Colorless Transmitter for WDM Networks. IEEE Photonics Technol. Lett. 2013, 25, 637-640. [CrossRef]

48. Petermann, K. Noise Characterstics of Solitary Laser Diodes. In Laser Diode Modulation and Noise; Okoshi, T., Ed.; Kluwer Academic Publishers: Dordrecht, The Netherlands, 1998; pp. 152-208.

49. Ma, Y.; Xu, Z.; Lin, H.; Zhou, M.; Wang, H.; Zhang, C.; Yu, J. Demonstration of Digital Fronthaul Over Self-Seeded WDM-PON in Commercial LTE Environment. Opt. Express 2015, 23, 11927-11935. [CrossRef] [PubMed]

50. Gebrewold, S.A.; Marazzi, L.; Parolari, P.; Brenot, R.; Duill, P.O.S.; Bonjour, R.; Hillerkuss, D.; Hafner, C.; Leuthold, J. Reflective-SOA Fiber Cavity Laser as Directly Modulated WDM-PON Colorless Transmitter. IEEE J. Sel. Top. Quantum Electron. 2014, 20, 1-9. [CrossRef]

51. Gebrewold, S.A.; Marazzi, L.; Parolari, P.; Brunero, M.; Brenot, R.; Hillerkuss, D.; Hafner, C.; Leuthold, J. Colorless Self-Seeded Fiber Cavity Laser Transmitter for WDM-PON. In Proceedings of the CLEO: Science and Innovations, San Jose, CA, USA, 8-13 June 2014; STu1J.4.

52. André, N.S.; Habel, K.; Louchet, H.; Richter, A. Adaptive Nonlinear Volterra Equalizer for Mitigation of Chirp-Induced Distortions in Cost Effective IMDD OFDM Systems. Opt. Express 2013, 21, 26527-26532. [CrossRef] [PubMed]

53. Simon, G.; Saliou, F.; Chanclou, P.; Deniel, Q.; Erasme, D.; Brenot, R. 70 km external cavity DWDM sources based on O-band Self Seeded RSOAs for transmissions at 2.5 Gbit/s. In Proceedings of the Optical Fiber Communication Conference, San Francisco, CA, USA, 9-13 March 2014; W3G.5.

54. Zhang, L.M.; Kschischang, F.R. Staircase Codes with 6\% to 33\% Overhead. J. Lightwave Technol. 2014, 32, 1999-2002. [CrossRef]

55. Bonk, R.; Brenot, R.; Meuer, C.; Vallaitis, T.; Tussupov, A.; Rode, J.C.; Sygletos, S.; Vorreau, P.; Lelarge, F.; Duan, G.H.; et al. 1.3/1.5 $\mu \mathrm{m}$ QD-SOAs for WDM/TDM GPON with Extended Reach and Large Upstream/Downstream Dynamic Range. In Proceedings of the Optical Fiber Communication-Incudes post deadline papers, San Diego, CA, USA, 22-26 March 2009; OWQ1. 